\title{
Care-seeking behaviour of adolescents with knee pain: a population-based study among 504 adolescents
}

Michael S Rathleff ${ }^{1,2^{*}}$, Sune K Skuldbø|' ${ }^{3}$, Mads N B Rasch ${ }^{3}$, Ewa M Roos ${ }^{4}$, Sten Rasmussen ${ }^{2}$ and Jens L Olesen ${ }^{3}$

\begin{abstract}
Background: Knee pain is common during adolescence. Adolescents and their parents may think that knee pain is benign and self-limiting and therefore avoid seeking medical care. However, long-term prognosis of knee pain is not favourable and treatment seems to offer greater reductions in pain compared to a "wait-and-see" approach. The purpose of this study was to describe the determinants of care-seeking behaviour among adolescents with current knee pain and investigate what types of treatment are initiated.

Methods: An online questionnaire was forwarded to 2,846 adolescents aged 15-19 in four upper secondary schools. The questionnaire contained questions on age, gender, height, weight, currently painful body regions, frequency of knee pain, health-related quality of life measured by the EuroQol 5-dimensions, sports participation and if they had sought medical care. Adolescents who reported current knee pain at least monthly or more frequently were telephoned. The adolescents were asked about pain duration, onset of knee pain (traumatic or insidious) and if they were currently being treated for their knee pain.
\end{abstract}

Results: 504 adolescents currently reported at least monthly knee pain. 59\% of these had sought medical care and $18 \%$ were currently under medical treatment. A longer pain duration and higher pain severity increased the odds of seeking medical care. Females with traumatic onset of knee pain were more likely to have sought medical care than females with insidious onset of knee pain. Females with traumatic onset of knee pain and increased pain severity were more likely to be undergoing medical treatment. The most frequently reported treatments were the combination of exercises and orthotics (68\% of those undergoing medical treatment).

Conclusion: Females with insidious onset of knee pain do not seek medical care as often as those with traumatic onset and adolescents of both genders with insidious onset are less likely to be under medical treatment. These findings are important as knee pain with insidious onset has similar consequences as knee pain with traumatic onset regarding pain severity, pain duration and reductions in health-related quality of life.

Keywords: Adolescents, Knee pain, Care-seeking, Treatment

\section{Background}

Epidemiological studies show that adolescent self-reported pain is frequent [1]. One of the most prevalent regions of pain is the knee [2-4]. Between 19 and $31 \%$ of adolescents report knee pain $[3,5,6]$ with Patellofemoral Pain (PFP) being one of the most common knee conditions among adolescents with a prevalence of approximately $7 \%[6-8]$.

\footnotetext{
* Correspondence: misr@rn.dk

'Health, Aarhus University, Aarhus, Denmark

${ }^{2}$ Orthopaedic Surgery Research Unit, Aalborg University Hospital, Aalborg, Denmark

Full list of author information is available at the end of the article
}

Adolescents may develop knee pain after a sudden unexpected traumatic injury or with an insidious slowly developing onset where the adolescent or parent does not know what initiated the pain [9]. An insidious onset of knee pain among adolescents is usually regarded as self-limiting and therefore intervention has been questioned [10-12].

Adolescent knee pain does not always have a favourable long-term prognosis. Nimon et al. [13] followed a group of females with insidious onset of anterior knee pain and found that $78 \%$ still reported knee pain after 14-20 years [13]. Longer pain duration before initiation of treatment is
C Biomed Central 
associated with poorer long-term prognosis among patients with PFP [14] and treatment by foot orthotics results in greater reductions in pain compared to a "wait-and-see" approach [15]. As the long-term prognosis of knee pain is not favourable and treatment seems to offer greater reductions in pain compared to a "wait-and-see" approach [15], it is important to investigate the care-seeking behaviour among adolescents with knee pain and what types of treatment are initiated.

The purpose of this study was therefore to describe the determinants of care-seeking behaviour among adolescents with current knee pain and to investigate how many adolescents with current knee pain are currently under medical treatment for their knee pain.

\section{Methods}

\section{Design}

Adolescents were recruited from a population-based cohort (Adolescent Pain in Aalborg 2011, the APA2011cohort), which consists of 4,007 adolescents aged 1219 years. In this analysis, only adolescents from the upper secondary schools were included (2,846 adolescents, $71 \%$ of the entire cohort) [16]. Two papers have previously been published from the APA2011-cohort. They describe pain and muscular mechanisms in the subsample diagnosed with PFP $[8,17]$. Ethical approval was obtained from the local ethics committee in the North Denmark Region (N-20110020). The ethics committee did not require an individual signed consent, but required that the schools informed the parents about the study and that participation in the study was voluntary. The reporting of the study follows the "Strengthening the Reporting of Observational studies in Epidemiology" (STROBE statement) [18].

\section{Study population}

There are four upper secondary schools in the area where the study was conducted. The four schools all have students from low, middle and high socioeconomic status. However no individual specific socioeconomic status was obtained. All four schools agreed to participate and all adolescents were invited to answer an online questionnaire as part of their physical education lessons. Adolescents currently exempted from physical education because of pain or similar conditions still participated in the study.

\section{Procedure}

Before data collection, the primary author [MSR] visited all schools that agreed to participate and told them about the purpose of the study and instructed them regarding the content of the questionnaire. A leaflet was distributed to adolescents with the title "Please help answer a questionnaire on a scientific study on physical activity, quality of life and pain". The leaflet contained information that the study was done by the Orthopaedic Surgery Research Unit at the University Hospital together with the Graduate School of Health Sciences at Aarhus University. In addition, a detailed description inside the leaflet contained information on the interest of the association between physical activity, quality of life and musculoskeletal pain, but especially knee pain.

The online questionnaire contained demographic questions on age, gender, height, weight, which school they attended, if they participated in sports in their leisure time and health related quality of life measured by the EuroQol 5-dimensions (EQ-5D) [19]. After answering these questions, the adolescents were presented with a pain mannequin. The pain mannequin was shown with a frontal and posterior view showing the front and the back of a human body divided into 12 predefined regions [20]. For further details on the online questionnaire and recruitment please refer to Rathleff et al. [16]. The adolescents were instructed to mark the regions where they experienced current pain [20] and report the frequency of pain (divided into: rarely, monthly, weekly, more than one time per week, almost daily pain) [21]. They were also asked if they had consulted their general practitioner (GP) regarding pain in that specific region.

\section{Adolescents with self-reported knee pain}

Adolescents who reported knee pain at least monthly, were telephoned by a physiotherapist. Adolescents who did not respond to our telephone call were called an additional two times. If the adolescents did not return our call, a text message was sent to their mobile telephone explaining that we would like to ask them a few additional questions regarding the online questionnaire. If the adolescents did not respond to the text message, they were called once more.

The physiotherapist asked the adolescent about 1) the time of onset of their current knee pain, 2) if the knee pain started after trauma or it had an insidious onset, and 3) if they were currently receiving treatment for their knee pain. If they were currently receiving treatment, they were asked by whom and which type of treatment they were receiving. All responses were transcribed as closely as possible to the adolescents` own wording to avoid interpretation bias.

\section{Interpretation of the adolescents' response}

Adolescents who reported knee pain with a duration of "a couple of years" was interpreted as 24 months. If they responded they had had pain for "as long as I can remember" or "always" it was interpreted as 120 months. If the adolescent could not remember how their knee pain started, the physiotherapist asked if they could remember a specific event where they first felt their knee 
pain. If the adolescent said no, they were asked if the knee pain slowly developed without a clear onset. If they did not know if their knee pain was related to a traumatic or insidious onset, it was interpreted as "insidious". A total of 11 adolescents could not remember if their knee pain was initiated by a traumatic event or it had an insidious onset and were therefore interpreted as "insidious onset".

All the following answers were interpreted as "currently under treatment": if the adolescents had received an exercise program by a physiotherapist or general practitioner (GP) and still performed the exercises; surgery and postoperative exercise; foot or knee orthotics prescribed by GP or physiotherapist; if the GP had prescribed NSAID. The following was interpreted as "not currently under treatment": if the adolescents reported they were referred for investigations at the hospital, by a GP or by a physiotherapist; if the adolescent reported they had consulted their GP and received advice to decrease physical activity.

\section{Data analysis}

Demographics, participation in sports, pain severity, pain duration, percentage who sought medical care, percentage who were under treatment and EQ-5D score were stratified for gender and onset of knee pain. Adolescents with traumatic onset of knee pain were compared with adolescents with insidious onset of knee pain using Student's t-test, Wilcoxon Rank Sum test or proportion test depending on data type. The association between "seeking medical care" and "currently under treatment", respectively, and the dependant variables: gender, EQ-5D (categorised in quartiles based on EQ-5D index score), body mass index (BMI; categorised into quartiles), pain duration, onset of pain (traumatic versus insidious onset) were tested through logistic regression analyses using robust variance estimates that adjust for within-cluster correlations within schools [22]. All 504 adolescents were included in both logistic regression analyses. Categorical dependent variables were entered into the logistic regression analyses by using dichotomous indicator variables using the built-in indicator function of Stata.

Furthermore "Contact to GP" was included in the model with the independent variable "currently under treatment". Model construction was done according to Hosmer and Lemeshow's "Purposeful selection of variables" [23]. Interaction between gender and all dependent variables were tested. Interaction between onset of knee pain and gender was found in the analysis with "seeking medical care" as the independent variable. $\mathrm{P}<0.05$ was considered statistically significant and no adjustments were made for multiple comparisons [24]. Stata (Version 11) was used for all statistical analyses.

\section{Results}

\section{Non-responder analysis}

From 2,846 potential responders, 2,200 adolescents answered the questionnaire corresponding to a response rate of $77 \%$. A total of 670 adolescents reported knee pain, at least monthly or more frequently. 60 adolescents did not report their telephone number in the questionnaire, leaving 610 potential responders. A total of 504 adolescents were successfully contacted by telephone (response rate of $83 \%$ of those who reported their telephone number; see Figure 1). A non-responder analysis using data from the online questionnaire was conducted. Responders $(\mathrm{n}=504)$ had a higher pain severity with $28 \%$ reporting daily pain versus only $15 \%$ among nonresponders (the other categories were: more than once per week $19 \%$ vs. $15 \%$, weekly $29 \%$ vs. $22 \%$, monthly $24 \%$ vs. $47 \%(\mathrm{p}<0.001)$. No difference was observed in gender distribution (70.5 vs. $73 \%, \mathrm{p}=0.583$ ), median BMI (21.58 vs. $21.38, \mathrm{p}=0.934)$ or average EQ-5D index score (0.75 vs. $0.78, \mathrm{p}=0.093)$ compared to non-responders $(\mathrm{n}=166)$.

\section{Demographics}

The majority of the sample was female with a median age of 17 (Table 1). A total of 158 (31.7\%) reported knee pain with traumatic onset while $346(68.3 \%)$ reported insidious onset of pain (Table 2). An unadjusted analysis showed no difference in pain frequency between those with traumatic onset of pain and those with insidious onset of pain $(\mathrm{p}=0.589)$.

\section{Seeking medical care}

$59 \%$ of the adolescents sought medical care for their knee pain. The unadjusted analysis showed that EQ-5D, pain severity, onset of knee pain and pain duration were associated with seeking medical care. The adjusted analysis showed that increased pain severity, longer pain duration and lower EQ5D index score increased the odds of having sought medical care (Table 3). There was a significant interaction between onset of pain and gender indicating females who had traumatic onset of knee pain were more likely to seek medical care than females with insidious onset of knee pain. This effect was not seen among males indicating that males with insidious onset of knee pain were as likely as those with traumatic onset of pain to seek medical care.

\section{Treatment}

47 adolescents with an insidious onset of knee pain were currently under treatment with 38 (81\%) of those receiving exercise, with or without the addition of surgery. An additional $6(13 \%)$ adolescents were referred for further investigation at the hospital and $3(13 \%)$ received advice from their GP on reducing their activity level. Among adolescents with traumatic onset of knee pain, 41 were 


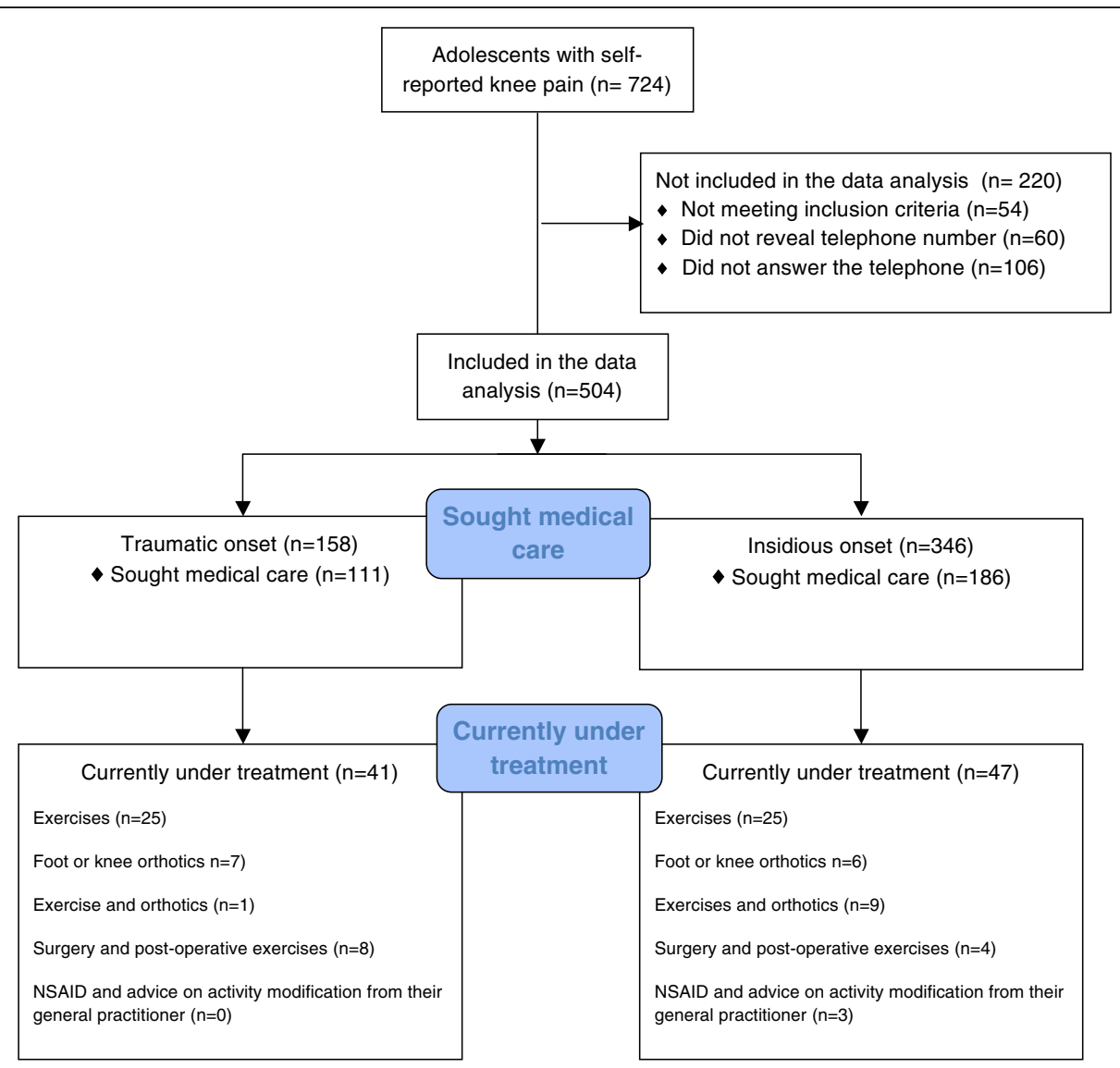

Figure 1 Flow-chart shows adolescents with an insidious or a traumatic onset of knee pain and the proportions that sought medical care and those who were currently being treated for their knee pain.

currently under treatment with 34 (83\%) receiving exercise, with or without the addition of surgery. An additional 8 (20\%) adolescents were referred for further investigation at the hospital (Figure 1).

The unadjusted analysis showed that EQ-5D, pain severity, onset of knee pain and contact to GP were associated with the odds of being under medical treatment. The adjusted analysis showed the 2nd and 3rd quartile BMI were more likely to be under treatment compared to the lowest quartile (Table 4). Adolescents with monthly knee pain were less likely to be under medical treatment compared with those with daily knee pain

Table 1 Demographics showing age, height, weight and Body Mass Index (BMI)*

\begin{tabular}{lll}
\hline & Females, $\mathbf{n}=\mathbf{3 6 3}$ & Males, $\mathbf{n}=\mathbf{1 4 1}$ \\
\hline Age [years], median and (IQR) & $17(16-18)$ & $17(17-18)$ \\
Height $[\mathrm{cm}]$, mean (SD) & $168.1( \pm 6.6)$ & $182.4( \pm 6.4)$ \\
Weight $[\mathrm{kg}]$, mean (SD) & $62.1( \pm 10.5)$ & $73.5( \pm 9.8)$ \\
BMl $\left[\mathrm{kg} / \mathrm{m}^{2}\right]$, median and $(\mathrm{IQR})$ & $21.8(20.2-23.8)$ & $21.5(19.6-23.5)$ \\
\hline
\end{tabular}

*Not cluster-adjusted.
(Table 4). Reporting traumatic onset of knee pain was associated with increased odds of being under medical treatment.

\section{Discussion}

The main findings are that lower EQ-5D index score, higher pain severity and traumatic onset of knee pain were associated with both seeking medical care and being under treatment. Females with insidious onset of knee pain do not seek medical care as often as females with traumatic onset and adolescents of both genders with insidious onset are less likely to be under medical treatment. These findings are important as knee pain with insidious onset has similar consequences as traumatic onset regarding pain severity, pain duration and reductions in health-related quality of life. This is the first study that investigates knee pain among adolescents recruited from a large population-based cohort. This method of recruitment offers a unique possibility to study adolescent knee pain without the potential selection bias occurring as a result of recruitment through GP or specialised sports medicine clinics. 
Table 2 Demographics and key variables stratified into gender and onset of knee pain*

\begin{tabular}{|c|c|c|c|c|c|c|}
\hline & \multicolumn{2}{|l|}{ Traumatic onset } & \multicolumn{2}{|l|}{ Insidious onset } & \multirow{2}{*}{$\begin{array}{l}\text { Comparison } \\
\text { between females }\end{array}$} & \multirow{2}{*}{$\begin{array}{l}\text { Comparison } \\
\text { between males }\end{array}$} \\
\hline & Female $(n=110)$ & Male $(n=50)$ & Female $(n=253)$ & Male $(n=91)$ & & \\
\hline Age [years] median and (IQR) & $17(17-18)$ & $18(17-18)$ & $17(16-18)$ & $17(17-18)$ & 0.138 & 0.132 \\
\hline Height $[\mathrm{cm}]$, mean $(95 \% \mathrm{Cl})$ & $168.2(166.9-169.5)$ & $182.7(181.1-184.9)$ & $168.1(167.2-168.9)$ & $182.3(181.0-183.6)$ & 0.903 & 0.720 \\
\hline Weight $[\mathrm{kg}]$, mean $(95 \% \mathrm{Cl})$ & $64.2(62.1-66.3)$ & $74.7(71.8-77.6)$ & $61.1(59.9-62.4)$ & $72.6(70.6-74.5)$ & 0.012 & 0.211 \\
\hline BMI $\left[\mathrm{kg} / \mathrm{m}^{2}\right]$, median (QR) & $22.1(20.2-24.8)$ & $22.2(20.7-24.5)$ & $21.1(19.5 .2-23.1)$ & $21.6(20.2-23.5)$ & 0.003 & 0.232 \\
\hline $\begin{array}{l}\text { Gender distribution [\% of all in } \\
\text { the cohort] }(95 \% \mathrm{Cl})\end{array}$ & $21.8(14.1-29.5)$ & $9.9(1.6-18.2)$ & $50.2(44.0-56.4)$ & $18.1(10.2-26.0)$ & $<0.0001$ & 0.19 \\
\hline $\begin{array}{l}\text { Participation in sports during leisure } \\
\text { time [\% who answered yes] }(95 \% \mathrm{Cl})\end{array}$ & $67.0(58.1-75.9)$ & $75.5(63.3-87.7)$ & $70.7(65.0-76.4)$ & $76.7(67.9-85.5)$ & 0.478 & 0.878 \\
\hline \multicolumn{7}{|l|}{ Pain frequency (\%) } \\
\hline Daily & 36.4 & 16.0 & 25.3 & 26.4 & 0.067 & 0.201 \\
\hline More than once per week & 17.3 & 14.0 & 23.3 & 13.1 & & \\
\hline Weekly & 30.0 & 30.0 & 26.9 & 36.3 & & \\
\hline Monthly & 16.4 & 41.0 & 24.5 & 24.2 & & \\
\hline $\begin{array}{l}\text { Pain duration [months], median } \\
\text { (IQR) }\end{array}$ & $24(12-42)$ & $18(10-36)$ & $24(12-48)$ & $24(12-42)$ & 0.382 & 0.241 \\
\hline $\begin{array}{l}\text { Have you sought medical care? } \\
{[\% \text { who replied yes] }(95 \% \mathrm{Cl})}\end{array}$ & $80.0(72.5-87.5)$ & $47.9(33.6-62.2)$ & $55.7(49.6-61.9)$ & $49.5(39.1-59.8)$ & $<0.0001$ & 0.863 \\
\hline $\begin{array}{l}\text { Currently under treatment? } \\
\text { [\% who replied yes] }(95 \% \mathrm{Cl})\end{array}$ & $28.2(19.7-36.6)$ & $20.0(8.8-31.2)$ & $13.4(9.2-17.7)$ & $14.3(7.0-21.5)$ & 0.0001 & 0.524 \\
\hline EQ-5D index score, median (IQR) & $0.78(0.71-0.82)$ & $0.78(0.76-0.82)$ & $0.78(0.72-0.82)$ & $0.78(0.78-0.82)$ & 0.246 & 0.8984 \\
\hline EQ-5D-vas, median (IQR) & $72(60-82)$ & $75(65-88)$ & $72(54-85)$ & $79(68-88)$ & 0.868 & 0.619 \\
\hline
\end{tabular}

*Not cluster adjusted.

\section{Care-seeking behaviour}

Almost $60 \%$ of the adolescents with knee pain had sought medical care. Care-seeking for knee pain seems similar to care-seeking for generalised pain, as the prevalence rates from this study are similar to those reported in previous studies of unspecific musculoskeletal pain. Roth-Isiqkeit et al. found that $51 \%$ of children and adolescents with pain had consulted their physician [25] while Perquin et al. [26] found that 57\% had contacted their GP [26]. A lower prevalence was found in a Finnish study where only $16 \%$ of males and $20 \%$ of females aged 16 had sought medical care [27]. This discrepancy may be attributed to differences in health care systems and the nature of the pain being studied [27].

Previous studies have reported similar determinants of seeking medical care among adolescents. These determinants were high frequency of pain, female gender, high BMI, and lower self-rated health [26]. However no one has previously investigated how the onset of pain is associated with care-seeking behaviour. We found increased odds of seeking medical care after knee pain with traumatic onset. This is a novel finding, however it resembles the findings by De Inocencio [28] who reported that physical trauma was the most common aetiology of pain among adolescents visiting a primary care physician for musculoskeletal pain.

It has been speculated that adolescents reporting pain after a trauma are more likely to be physically active and participate in organised sports [27]. Those participating in organised sports may be more aware of a cause or medical diagnosis for their pain condition and have better access to medical care because of their sports insurance. Sports insurance is required in some countries to participate in organised sports, but not in Denmark. Our results question this finding as we did not find an association between sports participation during leisure time and the odds of seeking medical care. Another more obvious explanation is that adolescents are more concerned about knee pain as a result of a traumatic event compared to insidious pain that slowly develops over time without a clear starting point.

\section{Treatment}

To our knowledge, no one has yet investigated which types of treatment are most frequently used to treat adolescents with knee pain in primary and secondary care. A study from Italy found that $96.8 \%$ of adolescents with non-specific musculoskeletal pain were advised to rest and use medication, seek physical therapy 
Table 3 Odds for having sought medical care

\begin{tabular}{|c|c|c|c|c|c|}
\hline & $\begin{array}{l}\text { Crude } \\
\text { OR }\end{array}$ & $\begin{array}{l}\text { p-value } \\
\text { OR }\end{array}$ & $\begin{array}{l}\text { Adjusted } \\
\text { OR }\end{array}$ & $\begin{array}{l}\text { p-value } \\
\text { Adj OR }\end{array}$ & $\begin{array}{l}\text { [95\% Cl] } \\
\text { Adj OR }\end{array}$ \\
\hline Older age (15 years of as referent) & 1.16 & 0.176 & 1.09 & 0.531 & $0.83-1.43$ \\
\hline Female gender & 1.79 & 0.056 & 1.21 & 0.564 & $0.63-2.34$ \\
\hline Participation in sports (compared to not participating in sports) & 0.76 & 0.182 & 1.01 & 0.957 & $0.70-1.45$ \\
\hline \multicolumn{6}{|l|}{ BMI (compared to $0-25 \%$ quartile, $16.18 ; 19.71$ ) } \\
\hline 2. quartile $(19.71 ; 21.55)$ & 1.03 & 0.881 & 0.93 & 0.824 & $0.48-1.78$ \\
\hline 3. quartile $(>21.55 ; 23.62)$ & 1.30 & 0.030 & 1.12 & 0.597 & $0.73-1.72$ \\
\hline 4. quartile (>23.62; 34.00) & 1.53 & 0.083 & 1.20 & 0.431 & $0.76-1.91$ \\
\hline \multicolumn{6}{|l|}{ EQ-5D index score (compared to $0-25 \%$ quartile, $-0.169 ; 0.723$ ) } \\
\hline $25-50 \%$ percentile $(>0.723 ; 0.776)$ & 0.64 & 0.066 & 0.93 & 0.765 & $0.57-1.50$ \\
\hline 50-75\% percentile $(>0.776 ; 0.824)$ & 0.34 & $<0.001$ & 0.66 & 0.013 & $0.48-0.92$ \\
\hline 75-100\% percentile (>0.824; 1.000) & 0.35 & 0.001 & 0.68 & 0.015 & $0.50-0.93$ \\
\hline \multicolumn{6}{|l|}{ Pain severity (compared to daily pain) } \\
\hline More than once per week & 0.41 & $<0.001$ & 0.45 & $<0.001$ & $0.29-0.69$ \\
\hline Weekly & 0.31 & $<0.001$ & 0.40 & $<0.001$ & $0.32-0.50$ \\
\hline Monthly & 0.15 & $<0.001$ & 0.19 & $<0.001$ & $0.11-0.32$ \\
\hline Pain duration (per 10 month increase) & 1.15 & $<0.001$ & 1.15 & $<0.001$ & $1.08-1.23$ \\
\hline Traumatic onset of pain (compared to an insidious onset) & 1.98 & 0.001 & & & \\
\hline Traumatic onset of knee pain compared to insidious onset among females & & & 2.75 & 0.031 & $1.10-6.91$ \\
\hline Traumatic onset of knee pain compared to insidious onset among males & & & 1.15 & 0.738 & $0.51-2.61$ \\
\hline
\end{tabular}

Univariate and multivariate logistic regression analysis. Crude OR shows the result from the univariate logistic regression analysis between "having sought medical care" and each of the explanatory variables. Adjusted coefficients show the results from the multivariate analysis.

Table 4 Odds for currently being under medical treatment

\begin{tabular}{|c|c|c|c|c|c|}
\hline & $\begin{array}{l}\text { Crude } \\
\text { OR }\end{array}$ & $\begin{array}{l}\text { p-value } \\
\text { OR }\end{array}$ & $\begin{array}{l}\text { Adjusted } \\
\text { OR }\end{array}$ & $\begin{array}{l}\text { p-value } \\
\text { Adj OR }\end{array}$ & $\begin{array}{l}{[95 \% \mathrm{Cl}]} \\
\text { Adj OR }\end{array}$ \\
\hline Older age (15 years of as referent) & 1.13 & 0.074 & 1.06 & 0.431 & $0.91-1.24$ \\
\hline Female gender & 1.26 & 0.068 & 0.97 & 0.871 & $0.70-1.34$ \\
\hline Participation in sports (compared to not participating in sports) & 0.66 & 0.320 & 0.77 & 0.529 & $0.34-1.73$ \\
\hline \multicolumn{6}{|l|}{ BMI (compared to $0-25 \%$ quartile, $16.18 ; 19.71$ ) } \\
\hline 2. quartile $(19.71 ; 21.55)$ & 1.64 & 0.015 & 1.75 & $<0.001$ & $1.30-2.35$ \\
\hline 3. quartile (>21.55; 23.62) & 1.81 & 0.010 & 1.56 & 0.016 & $1.08-2.25$ \\
\hline 4. quartile $(>23.62 ; 34)$ & 1.50 & 0.188 & 1.16 & 0.666 & $0.57-2.35$ \\
\hline \multicolumn{6}{|l|}{ EQ-5D index score (compared to $0-25$ quartile, $-0.169 ; 0.723$ ) } \\
\hline $25-50 \%$ quartile $(>0.723 ; 0.776)$ & 0.69 & 0.051 & 0.94 & 0.801 & $0.60-1.48$ \\
\hline 50-75 quartile (>0.776; 0.824) & 0.40 & $<0.001$ & 0.76 & 0.201 & $0.51-1.15$ \\
\hline $75-100 \%$ quartile $(>0.824 ; 1.000)$ & 0.77 & 0.338 & 1.47 & 0.067 & $0.97-2.21$ \\
\hline \multicolumn{6}{|l|}{ Pain severity (compared to daily pain) } \\
\hline More than once per week & 0.48 & $<0.001$ & 0.59 & $<0.001$ & $0.45-0.75$ \\
\hline Weekly & 0.40 & $<0.001$ & 0.53 & $<0.001$ & $0.38-0.76$ \\
\hline Monthly & 0.17 & $<0.001$ & 0.25 & 0.002 & $0.11-0.59$ \\
\hline Pain duration (per 10 month increase) & 1.05 & 0.131 & 1.01 & 0.737 & $0.95-1.08$ \\
\hline Traumatic onset of pain (compared to an insidious onset) & 2.27 & 0.032 & 2.24 & 0.034 & $1.06-4.72$ \\
\hline Contact to GP & 5.04 & $<0.001$ & 3.64 & 0.002 & 1.64- 8.08 \\
\hline
\end{tabular}

Univariate and multivariate logistic regression analysis. Crude OR shows the result from the univariate logistic regression analysis between "being under medical treatment" and each of the explanatory variables. Adjusted coefficients show the results from the multivariate analysis. 
and rehabilitation, or a combination of these [29]. However they also found that only $70 \%$ of the adolescents complied with the advice. This may suggest that some of the adolescents from the current study sought medical care from their GP and were advised to visit a physiotherapist or reduce activity. However, the adolescents may not have followed the prescription or simply did not consider the "advice" a valid treatment. This may lead to an underreporting of the proportion currently being treated for their knee pain.

Another study investigated medical consumption for chronic non-specific pain among adolescents [26]. They found that pain intensity increased the usage of medication for treating adolescent pain. We also found that increased pain severity increased the odds of currently being treated for knee pain. In addition, we observed that a traumatic onset of knee pain increased the odds of currently being under medical treatment, even after adjusting for pain severity, EQ-5D and contact with their GP. This might be attributed to factors related to the adolescent, the GP or the severity of the injury.

\section{Strengths and weaknesses of the study}

All data were self-reported and we did not obtain information from either parents or general practitioners. We used simple questions using a standardised electronic questionnaire protocol, but there could be some adolescents who misunderstood our questions. This can lead to misclassification bias. The cross-sectional design of the study increases the risk of recall bias and thereby the validity of our data on care-seeking behaviour, pain duration and onset of knee pain. The median pain duration was 24 months. Therefore, contacting the GP could have taken place a long time ago and the adolescents could have forgotten it. The same might hold true for the onset of knee pain. However, we do not believe that the information obtained on current treatment is influenced by such a bias, as this information is related to the present and involves no recall. No information was collected on which specific GP the adolescent was listed with. There may be a wide variation in GPs' diagnosis and prescribed treatments and future studies should control for the potential heterogeneity between GPs.

One of the strengths of the study is that Danish citizens have free and unlimited access to health care through the GP. Therefore the care-seeking behaviour is not biased due to unequal access to health care. However, even though Denmark offers equal free access to heath care through the GP, we cannot rule out that socioeconomic state may influence our results. Although the equal access improves the external validity of the results to countries with similar health care systems, our findings may not be generalisable to countries with unequal access to health care.

\section{Implications for clinicians and researchers}

General practitioners, adolescents and parents need to be aware that knee pain with insidious onset may be equally serious as knee pain with traumatic onset regarding pain severity, pain duration and reductions in health-related quality of life. Longer pain duration seems to be associated with a poorer long-term prognosis after initiation of treatment [14,30]. This seems to hold true for many different musculoskeletal disorders, including knee pain, and health personnel involved in treating adolescents with knee pain should consider intervening at an early stage of symptom onset From a research perspective, our findings are important as they suggest that recruitment of adolescents with knee pain should be done through population-based cohorts to avoid selection bias. The data from our study show that not all adolescents with knee pain will contact their GP. $40 \%$ of the true population would not be included if recruitment was done through the GP. The population-based recruitment used in the current study will enable future studies with high external validity.

\section{Future research}

A large percentage of the adolescents had sought medical care, but only $18 \%$ were currently being treated, even though they all reported current knee pain. Future studies should aim to prospectively describe the clinical pathway of adolescents with knee pain in primary care and survey the number of consultations, the types of prescribed treatment and compliance. Further, we need to describe the reasons for treatment termination in primary and secondary care and investigate if it is related to an absence of pain or because no further reductions in pain can be achieved by intervening.

\section{Conclusion}

Females with insidious onset of knee pain do not seek medical care as often as those with traumatic onset and adolescents of both genders with insidious onset are less likely to be under medical treatment. These findings are important as knee pain with insidious onset has similar consequences as knee pain with traumatic onset regarding pain severity, pain duration and reductions in healthrelated quality of life.

\section{Competing interests}

The authors declare that they have no competing interests.

\section{Authors' contributions}

MSR planned the study together with EMR, SR and JLO. MSR, SKK, MNBR and JLO helped collect the data. MSR made the first draft of the result section while EMR, SR, JLO, SKK and MNBR provided important feedback on the interpretation of the results. MSR wrote the first draft of the manuscript while EMR, SR, JLO, SKK and MNBR provided feedback on the draft. All authors read and approved the final manuscript. 


\section{Author details}

${ }^{1}$ Health, Aarhus University, Aarhus, Denmark. ${ }^{2}$ Orthopaedic Surgery Research Unit, Aalborg University Hospital, Aalborg, Denmark. ${ }^{3}$ Department of Rheumatology, Aalborg University Hospital, Aalborg, Denmark. ${ }^{4}$ Institute of Sports Science and Clinical Biomechanics, University of Southern Denmark, Odense, Denmark.

Received: 29 March 2013 Accepted: 29 July 2013

Published: 30 July 2013

\section{References}

1. King S, Chambers CT, Huguet A, MacNevin RC, McGrath PJ, Parker L, MacDonald AJ: The epidemiology of chronic pain in children and adolescents revisited: a systematic review. Pain 2011, 152:2729-2738.

2. McGrath PA, Speechley KN, Seifert CE, Biehn JT, Cairney AE, Gorodzinsky FP, Dickie GL, McCusker PJ, Morrissy JR: A survey of children's acute, recurrent, and chronic pain: validation of the pain experience interview. Pain 2000 87:59-73.

3. Fairbank JC, Pynsent PB, van Poortvliet JA, Phillips $\mathrm{H}$ : Mechanical factors in the incidence of knee pain in adolescents and young adults. J Bone Joint Surg Br 1984, 66:685-693.

4. Stovitz SD, Pardee PE, Vazquez G, Duval S, Schwimmer JB: Musculoskeletal pain in obese children and adolescents. Acta Paediatr 2008, 97:489-493.

5. Vahasarja V: Prevalence of chronic knee pain in children and adolescents in northern Finland. Acta Paediatr 1995, 84:803-805.

6. Molgaard C, Rathleff MS, Simonsen O: Patellofemoral pain syndrome and its association with hip, ankle, and foot function in 16- to 18-year-old high school students: a single-blind case-control study. J Am Podiatr Med Assoc 2011, 101:215-222.

7. Barber Foss KD, Myer GD, Chen SS, Hewett TE: Expected prevalence from the differential diagnosis of anterior knee pain in adolescent female athletes during preparticipation screening. J Athl Train 2012, 47:519-524.

8. Rathleff MS, Roos EM, Olesen JL, Rasmussen S, Arendt-Nielsen L: Lower mechanical pressure pain thresholds in female adolescents with patellofemoral pain syndrome. J Orthop Sports Phys Ther 2013, 43(6):414-421

9. El-Metwally A, Salminen JJ, Auvinen A, Macfarlane G, Mikkelsson M: Risk factors for development of non-specific musculoskeletal pain in preteens and early adolescents: a prospective 1-year follow-up study. BMC Musculoskel Dis 2007, 8:46.

10. Utting MR, Davies $G$, Newman JH: Is anterior knee pain a predisposing factor to patellofemoral osteoarthritis? Knee 2005, 12:362-365.

11. van Dijk CN, van der Tempel WM: Patellofemoral pain syndrome. BMJ 2008, 337:a1948.

12. Insall JN: Surgery of the knee. New York: Churcill Livingstone; 1984.

13. Nimon G, Murray D, Sandow M, Goodfellow J: Natural history of anterior knee pain: a 14- to 20-year follow-up of nonoperative management. J Pediatr Orthop 1998, 18:118-122.

14. Collins NJ, Bierma-Zeinstra SM, Crossley KM, van Linschoten RL, Vicenzino B, van Middelkoop M: Prognostic factors for patellofemoral pain: a multicentre observational analysis. Br J Sports Med 2013, 47(4):227-233.

15. Mills K, Blanch $P$, Dev $P$, Martin M, Vicenzino B: A randomised control trial of short term efficacy of in-shoe foot orthoses compared with a wait and see policy for anterior knee pain and the role of foot mobility. $\mathrm{Br} J$ Sports Med 2012, 46:247-252.

16. Rathleff MS, Roos EM, Olesen $J$, Rasmussen S: Early intervention for adolescents with Patellofemoral Pain Syndrome - a pragmatic cluster randomised controlled trial. BMC Musculoskel Dis 2012, 13:9.

17. Rathleff MS, Samani A, Olesen JL, Roos EM, Rasmussen S, Christensen BH, Madeleine P: Neuromuscular activity and knee kinematics in adolescents with patellofemoral pain. Med Sci Sports Exerc 2013. Epub ahead of print.

18. von Elm E, Altman DG, Egger M, Pocock SJ, Gotzsche PC, Vandenbroucke JP: The Strengthening the Reporting of Observational Studies in Epidemiology (STROBE) statement: guidelines for reporting observational studies. J Clin Epidemiol 2008, 61:344-349.

19. Rabin R, de Charro F: EQ-5D: a measure of health status from the EuroQol Group. Ann Med 2001, 33:337-343.

20. van den Hoven LH, Gorter KJ, Picavet HS: Measuring musculoskeletal pain by questionnaires: the manikin versus written questions. EurJPain 2010, 14:335-338.
21. Stahl M, Mikkelsson M, Kautiainen H, Hakkinen A, Ylinen J, Salminen JJ: Neck pain in adolescence. A 4-year follow-up of pain-free preadolescents. Pain 2004, 110:427-431.

22. Williams RL: A note on robust variance estimation for cluster-correlated data. Biometrics 2000, 56:645-646.

23. Bursac Z, Gauss CH, Williams DK, Hosmer DW: Purposeful selection of variables in logistic regression. Source Code Biol Med 2008, 3:17.

24. Rothman KJ: No adjustments are needed for multiple comparisons. Epidemiology 1990, 1:43-46.

25. Roth-Isigkeit A, Thyen U, Stoven H, Schwarzenberger J, Schmucker P: Pain among children and adolescents: restrictions in daily living and triggering factors. Pediatrics 2005, 115:e152-e162.

26. Perquin CW, Hazebroek-Kampschreur AA, Hunfeld JA, van Suijlekom-Smit LW, Passchier J, van der Wouden JC: Chronic pain among children and adolescents: physician consultation and medication use. Clin J Pain 2000, 16:229-235.

27. Paananen MV, Taimela SP, Tammelin TH, Kantomaa MT, Ebeling HE, Taanila AM, Zitting PJ, Karppinen Jl: Factors related to seeking health care among adolescents with musculoskeletal pain. Pain 2011, 152:896-903.

28. De Inocencio J: Epidemiology of musculoskeletal pain in primary care. Arch Dis Child 2004, 89:431-434.

29. Masiero S, Carraro E, Sarto D, Bonaldo L, Ferraro C: Healthcare service use in adolescents with non-specific musculoskeletal pain. Acta Paediatr 2010, 99:1224-1228

30. Mallen CD, Peat G, Thomas E, Dunn KM, Croft PR: Prognostic factors for musculoskeletal pain in primary care: a systematic review. $\mathrm{Br} J \mathrm{Gen}$ Pract 2007, 57:655-661.

doi:10.1186/1471-2474-14-225

Cite this article as: Rathleff et al: Care-seeking behaviour of adolescents with knee pain: a population-based study among 504 adolescents. BMC Musculoskeletal Disorders 2013 14:225.

\section{Submit your next manuscript to BioMed Central and take full advantage of:}

- Convenient online submission

- Thorough peer review

- No space constraints or color figure charges

- Immediate publication on acceptance

- Inclusion in PubMed, CAS, Scopus and Google Scholar

- Research which is freely available for redistribution

Submit your manuscript at www.biomedcentral.com/submit
C) Biomed Central 